\title{
A Celeuma em Torno da Temática do Planejamento Didático-Pedagógico: Definição e Caracterização de seus Elementos Constituintes
}

\section{A Disarray Around the Theme of Lesson Planning: Definition and Characterization of its Constituent Elements}

\author{
Milena Alves ${ }^{(1)}$ Brasil \\ Amadeu Moura Bego ${ }^{(1)}$ Brasil
}

Este trabalho tem como objetivo investigar os diferentes sentidos que os elementos do planejamento didático-pedagógico têm assumido nos trabalhos da área de Ensino de Ciências e propor, a partir de uma perspectiva crítica, a delimitação de seus elementos constituintes essenciais, bem como suas definições. Para tanto, realizou-se uma revisão sistemática da literatura que envolveu a análise de 403 trabalhos oriundos: de periódicos da área de Ensino nos estratos A1 e A2; de anais de eventos da área de Ensino e Educação; e do catálogo de teses e dissertações da CAPES. Foram selecionados trabalhos relativos aos anos de 2012 a 2016. Constatou-se a ausência de equivalência terminológica para os termos estratégia, metodologia, método, técnica e recurso. Além disso, a maioria absoluta dos trabalhos utiliza esses termos desvinculados de definições e referenciais teóricos. Posteriormente, propôs-se definições, teoricamente fundamentadas, para cada um dos termos no contexto do planejamento. Defende-se que a abordagem metodológica orienta o processo de ensino e aprendizagem e consiste em um elemento essencial do planejamento, que envolve a explicitação de concepções de fundo sobre o ensino e a aprendizagem, a natureza da ciência e o papel social da educação escolar. Por isso, o planejamento necessita ser um ato consciente do professor, em que ele explicita e se conscientiza sobre a abordagem metodológica a ser adotada. Essa abordagem orientará a delimitação dos objetivos de aprendizagem, a seleção e a estruturação das estratégias didáticas e de avaliação, bem como os recursos didáticos e materiais de aprendizagem demandados.

Palavras-chave: estratégia didática; metodologia; recursos didáticos; método; técnica.

This paper aims to investigate the different meanings that the constituent elements of lesson planning have assumed in the works of Science Education and proposes, from a critical approach, the delimitation of its essential constituent elements, as well as their definitions. To this end, a systematic literature review was performed, involving the analysis of 403 papers from: Science Education journals in strata A1 and A2; 
Proceedings of Teaching and Education meetings; and theses and dissertations from the CAPES catalog. Studies were selected from 2012 to 2016. An absence of terminological equivalence was found for the terms strategy, methodology, method, technique, and resource. In addition, most of the papers use these terms unlinked from their definitions and any theoretical frameworks. Subsequently, theoretically grounded definitions were proposed for each of the terms in the context of lesson planning. It is argued that the methodological approach guides the teaching and learning process and consists of an essential element of lesson planning, which involves explaining the background conceptions about teaching and learning, the nature of science, and the social role of school education. Therefore, planning a lesson needs to be an explicit and conscious act of the teacher, in which he becomes aware of the methodological approach to be adopted. This approach will guide the requirement for the delimitation of learning objectives, the selection and arrangement of instructional and assessment strategies, as well as the teaching resources and instructional materials.

Keywords: instructional strategy; methodology; teaching resources; method; technique.

\section{Os elementos do planejamento didático-pedagógico}

O planejamento do professor, algumas vezes, é centrado na definição de atividades de ensino e/ou no conteúdo programático. Além disso, o planejamento é elaborado baseado em apenas único livro didático e, geralmente, apresenta objetivos de aprendizagem implícitos ou não tão claros (Sánchez Blanco, \& Valcárcel Pérez, 1999; Ustra, \& Hernandes, 2010).

Todavia, contemporaneamente, concebe-se que o ato de planejar pode se constituir em um processo em evolução e um desencadeador de inovações (Menegolla, \& Sant’Anna, 2014). Tais entendimentos, colocam o planejamento em uma posição fundamental no processo de ensino e aprendizagem, sendo compreendido como dimensão responsável por definir o trabalho do professor, bem como uma ação reflexiva e contínua do professor, a qual envolve escolhas metodológicas e teóricas (Farias, Sales, Braga, \& França, 2011; Bego, 2013).

Nesse contexto, Amaral (2006) elenca os elementos que compõem um bom planejamento, tais como: conteúdo, método, técnica e recurso didático. Anastasiou e Alves (2004), por sua vez, enumeram como elementos do planejamento metodologia, estratégias e instrumentos. Sanmartí (2002) destaca como elementos importantes do planejamento a definição dos objetivos e a distribuição do tempo. Finalmente, Libâneo (2013) cita objetivos, conteúdos, métodos, formas organizativas e avaliação como elementos essenciais do planejamento.

Nota-se que há diferentes perspectivas acerca de quais elementos devem ser considerados durante a elaboração dos planejamentos. No entanto, é também possível observar que alguns elementos são tidos como fundamentais. Dessa forma, alguns elementos são apontados como básicos, tais como: a definição dos objetivos e dos 
conteúdos, a metodologia, as estratégias didáticas, os recursos didáticos e as estratégias de avaliação (Amaral, 2006; Anastasiou, \& Alves, 2004; Castro, Tucunduva, \& Arns, 2008; Farias et al., 2011; Libâneo, 2013; Piletti, 2004).

A busca pela definição desses termos e conceitos, porém, retorna algumas divergências e conceituações polissêmicas. Ademais, observa-se que, com frequência, termos diversificados têm sido utilizados como o mesmo sentido. São encontrados na literatura termos distintos com acepções variadas, segundo alguns teóricos (Farias et al., 2011; Leal, 2005; Delizoicov, \& Angotti, 1992), para se referir a um mesmo objeto. A título de exemplo, Farias e colaboradores (2011) classificam seminários, júri simulado, debates, exposições orais e outras como estratégias didáticas. Todavia, Leal (2005) classifica esses mesmos termos como metodologias de ensino. E, ainda, Delizoicov e Angotti (1992) utilizam técnicas de ensino para se referirem a esses mesmos termos.

Tal observação corrobora, por exemplo, a afirmação de Vieira e Vieira (2005) sobre o uso difuso do termo estratégia. De acordo com os autores, o termo estratégia "tem sido utilizado numa multiplicidade de contextos, realidades e com muitas acepções" (p. 15). Os autores afirmam ainda que, no campo educacional, o termo está associado a muitos sinônimos, tais como: abordagem, atividade, habilidade, método, modelo, técnica e tática.

A utilização polissêmica e indistinta para os termos dos elementos do planejamento é, também, uma preocupação para Araujo (2012). O autor alerta que “[...] há uma diversidade de classificações que se envolvem em distinções preocupadas com as particularidades e com as peculiaridades metodológicas do ensino" (p. 25).

As informações apresentadas acima destacam que tem havido, em demasiado, conflitos de definições e a utilização acrítica dos termos referentes aos elementos do planejamento didático-pedagógico, indicando pouca preocupação com seus significados dentro de um coerente quadro teórico.

Vigotski (2009), em um contexto de desenvolvimento da psicologia no começo do século XX, ressaltava a necessidade de clareza e equivalência terminológica para algumas áreas do saber. Para o autor "[...] a confusão começa pela imprecisão terminológica [...]" e, posteriormente, "[...] surge toda uma série de mal-entendidos, uma vez que os estudiosos discutem frequentemente sobre diferentes objetos, mas os nomeiam com o mesmo termo" (p. 422). De acordo com Vigotski (2009), a utilização de expressões descontextualizadas acaba por gerar divergências entre o sentido que se pretende propor e o sentido que se pretende atribuir em um determinado campo de estudo. Portanto, a consolidação dos conceitos se daria a partir do estabelecimento de relações e derivações com outros conceitos em uma determinada estrutura teórica.

Entende-se, assim, que este trabalho traz contribuições para a área de Ensino de Ciências uma vez que pretende propor definições mais criteriosas e embasadas para os elementos do planejamento didático-pedagógico em uma determinada perspectiva. Tal objetivo se justifica, como apresentado, pelo fato de que o uso de expressões descontextualizadas pode gerar divergências entre o sentido que se pretende atribuir 
e o sentido que se propõe dentro da área. Isso pode tornar o programa de pesquisa na área do planejamento de ensino difícil de se consolidar, bem como a realização de revisões bibliográficas que possibilitariam a produção de trabalhos de estado da arte sobre a temática.

Dentre as formas de revisão da literatura, a revisão sistemática é, segundo Costa e Zoltowski (2014), um método que possibilita potencializar levantamentos bibliográficos em função do aumento do número de resultados de uma forma organizada. Os autores discutem algumas vantagens da realização de revisões sistemáticas: i) não constituem uma simples relação cronológica ou uma exposição linear e descritiva de uma temática, mas sim trabalhos reflexivos e críticos; ii) reúnem avaliações críticas de trabalhos já publicados, identificando relações, contradições, lacunas e inconsistências na área, além, é claro, de possivelmente indicar sugestões para a resolução de problemas; iii) minimizam o risco de que a busca fique enviesada, já que é possível que o autor, ao realizar uma revisão tradicional, supervalorize estudos que corroborem apenas suas hipóteses iniciais.

Diante do exposto, pretende-se neste trabalho teórico-bibliográfico realizar uma revisão bibliográfica sistemática dos diferentes sentidos que os termos dos elementos do planejamento didático-pedagógico têm assumido, de modo específico, na área de Ensino de Ciências. Em seguida, a partir de uma perspectiva crítica, propõe-se a delimitação dos elementos constituintes essenciais do planejamento de ensino, bem como suas definições conceituais.

\section{Procedimentos metodológicos}

Este é um trabalho de pesquisa de natureza teórico-bibliográfica que objetiva apresentar os resultados quali e quantitativos de uma revisão sistemática sobre as acepções para os termos dos elementos do planejamento didático-pedagógico e, em seguida, propor definições conceituas, teoricamente fundamentadas, para esses termos.

A metodologia de análise dos dados utilizada foi a análise de conteúdo (AC), segundo a proposta de Bardin (2016). A autora define a AC como:

Um conjunto de técnicas de análise das comunicações visando obter por procedimentos sistemáticos e objetivos de descrição do conteúdo das mensagens indicadores (quantitativos ou não) que permitam a inferência de conhecimentos relativos às condições de produção/recepção (variáveis inferidas) dessas mensagens (Bardin, 2016, p. 48).

Para a realização da revisão sistemática, foram selecionadas revistas brasileiras na área de Ensino, de estrato A1 e A2, haja vista serem as revistas melhores conceituadas pelo Qualis da Capes. O Qualis é o conjunto de procedimentos utilizados pela Capes para estratificação da qualidade da produção intelectual dos programas de pós-graduação e é baseado nas informações fornecidas pelos programas da área na plataforma Sucupira, ano a ano. A sua função é apoiar os comitês de avaliação no processo de qualificação e análise da produção bibliográfica de docentes e discentes dos programas de pós- 
graduação credenciados pela Capes (Barradas Barata, 2016). Os dados refletem os principais periódicos em que os docentes da área têm publicado os resultados de suas pesquisas. Os critérios utilizados para a avaliação são a indexação, o escopo e o índice e mediana h5 nas métricas do Google Scholar dos periódicos (Araújo-Jorge, Borba, \& Sovierzoski, 2016).

Assim, apesar da ampla discussão em torno do processo de construção do indicador (Barradas Barata, 2016), mas reconhecendo-se que o Qualis é o conjunto de procedimentos utilizados oficialmente pela Capes e legitimados pela comunidade da área, realizou-se a busca dos periódicos de Ensino de Ciências classificados como A1 e A2.

A pesquisa da classificação dos estratos dos periódicos foi realizada no website da Plataforma Sucupira, considerando a avaliação do quadriênio 2013-2016, especificamente para a área de avaliação Ensino.

Para o estrato A1, foram obtidas 145 ocorrências com diferentes temáticas educacionais. Dessas revistas, Ciência e Educação (C\&E) e Ensaio: Pesquisa em Educação em Ciências são revistas brasileiras e destacam-se por representarem publicações com foco direcionado, de maneira explícita, ao Ensino de Ciências e, por isso, foram selecionadas como fonte de busca. Já para o estrato A2, no mesmo período, foram listados 198 periódicos, dos quais 12 são da área de Ensino de Ciências, os quais foram selecionados: Revista Brasileira de Ensino de Ciência e Tecnologia (RBECT); Revista Brasileira de Pesquisa em Educação em Ciências (RBPEC); Revista de Educação, Ciências e Matemática (RECM); Revista de Ensino de Ciências e Matemática (REnCiMa); Investigações em Ensino de Ciências (IENCI); Acta Scientae; Alexandria; Amazônia Revista de Educação em Ciências e Matemática; Areté- Revista Amazônica de Ensino de Ciências; Dynamis; Praxis; Vidya. Optou-se por excluir as revistas de estrato A1 e A2 com escopo particular do Ensino de Física, Matemática e Saúde, por exemplo, dada as especificidades dos trabalhos.

Adicionalmente, a fim de investigar como tem sido a utilização dos termos pela comunidade científica mais ampla, realizou-se a busca nos anais dos eventos da área de Ensino de Ciências e de Educação. Tal busca se justificou por sua importância para o desenvolvimento de pesquisas na área de Ensino de Ciências e afins, devido à crescente quantidade de trabalhos submetidos e, também, por promoverem uma ampla e massiva participação dos membros da comunidade científica. Esses fatos podem indicar que os trabalhos enviados a esses eventos são resultados da popularização e ampla disseminação dos conhecimentos gerados na academia e, portanto, podem apontar possíveis tendências de utilização dos termos de interesse. Os anais dos eventos analisados foram: Associação Nacional de Pós-Graduação e Pesquisa em Educação (ANPED); Encontro Nacional de Pesquisa em Educação em Ciências (ENPEC); e Encontro Nacional de Didática e Práticas de Ensino (ENDIPE). No mesmo sentido, estendeu-se a busca, por fim, ao catálogo de teses e dissertações da CAPES.

A escolha dos termos para a busca foi realizada por meio de uma técnica da 
AC denominada "leitura flutuante", a qual, segundo Bardin (2016), é uma etapa que "consiste em estabelecer contato com os documentos a analisar e em conhecer o texto deixando-se invadir por impressões e orientações" (p. 126). Fizeram parte da etapa de leitura flutuante, livros e artigos das áreas de Educação e Ensino que discutiam, de maneira geral, os termos dos elementos do planejamento de ensino. Durante a leitura desses documentos foram sendo observados quais termos eram recorrentes e quais apareciam com diferentes definições e/ou classificações. Assim, definiu-se como critérios de escolha, a relevância e/ou importância dos termos para a área da Didática, no geral, e da Didática das Ciências, em particular. Além disso, a existência de definições incoerentes, divergentes e, até mesmo, sua ausência foi observada. Depois da leitura flutuante, os termos delimitados para a busca foram: metodologia, método, estratégia, técnica e recurso.

Como é possível notar, as fontes e origens dos trabalhos selecionados na busca são bastante diversificadas. Assim, em função do grande número de documentos retornados, decidiu-se pela delimitação temporal de 5 anos (2012 a 2016), objetivando verificar como, de forma mais recente, os termos têm sido utilizados na área.

Buscou-se os termos nos títulos e nas palavras-chave dos trabalhos disponíveis nos anais dos eventos, periódicos, dissertações e teses. As buscas nas revistas C\&E, Ensaio, RBPEC e IENCI, nos anais dos eventos e no catálogo de teses e dissertações foram realizadas nos meses de novembro de 2016 a janeiro de 2017, uma vez que fizeram parte de uma pesquisa de mestrado desenvolvida entre os anos de 2016 e 2018. Nas demais revistas, as buscas foram realizadas no ano de 2019 dada a necessidade de ampliação da revisão.

Após os procedimentos de revisão sistemática, realizou-se a proposição fundamentada dos termos no contexto do planejamento de ensino. Para essa proposição adotou-se, conforme procedimentos propostos por Rios (2006), a seguinte sistemática teórico-metodológica: busca pela origem etimológica das palavras, seguida de seu significado dicionarizado e, finalmente, a busca pelo sentido que os termos guardam em um contexto mais amplo e, posteriormente, no contexto da educação. A sistemática adotada se justifica por ser importante verificar as significações dos termos, indagando sobre seu aparecimento, permanência e transformações nos contextos em que são utilizados. O interesse era, efetivamente, encontrar a maneira como os termos são utilizados na área educacional, bem como definir "quais as implicações de sua utilização e de que maneira podemos evitar distorções, não apenas na configuração teórica, mas e principalmente - na prática que se desenvolve socialmente" (Rios, 2006, p. 67).

\section{Resultados da AC para os termos pesquisados}

A busca pelos termos (metodologia, método, estratégia, recurso e técnica) retornou 403 trabalhos que foram analisados segundo os preceitos da AC. Nas Tabelas 1 e 2 constam informações acerca da distribuição dos trabalhos segundo fonte e ano de publicação. 
Tabela 1. Distribuição quantitativa dos trabalhos no período de busca

\begin{tabular}{ccc}
\hline Base de dados & Trabalhos disponíveis & Trabalhos selecionados \\
\cline { 2 - 3 } CAPES & 390 & 54 \\
C\&E & 227 & $7(1,80 \%)$ \\
ENSAIO & 210 & $10(4,40 \%)$ \\
IENCI & 151 & $10(4,76 \%)$ \\
RenCiMA & 207 & $7(4,64 \%)$ \\
RBPEC & 190 & $10(4,83 \%)$ \\
RBECT & 130 & $24(12,6 \%)$ \\
RECM & 221 & $6(4,62 \%)$ \\
ACTA SCIENTAE & 83 & $11(4,98 \%)$ \\
AMAZÔNIA & 227 & $2(2,41 \%)$ \\
ARETÉ & 56 & $25(11,0 \%)$ \\
DYNAMIS & 114 & $4(7,14 \%)$ \\
PRAXIS & 120 & $16(14,0 \%)$ \\
VIDYA & 153 & $7(5,83 \%)$ \\
ALEXANDRIA & 192 & $3(1,96 \%)$ \\
ANPED & 3280 & $10(5,20 \%)$ \\
ENPEC & 4736 & $111(3,38 \%)$ \\
ENDIPE & $86(1,82 \%)$
\end{tabular}

${ }^{{ } \mathrm{O}}$ número de trabalhos disponíveis no Portal de Periódicos Capes é indeterminado, pois o website não fornece essa informação.

Fonte: Elaborada pelos autores.

Tabela 2. Distribuição quantitativa dos trabalhos segundo fonte e ano de publicação

\begin{tabular}{lccccc}
\hline \multirow{2}{*}{ Tipo de trabalho } & \multicolumn{7}{c}{ Ano } \\
\cline { 2 - 6 } & $\mathbf{2 0 1 2}$ & $\mathbf{2 0 1 3}$ & $\mathbf{2 0 1 4}$ & $\mathbf{2 0 1 5}$ & $\mathbf{2 0 1 6}$ \\
\hline Artigos de revista & 24 & 28 & 25 & 31 & 36 \\
Dissertações & 0 & 10 & 12 & 5 & 18 \\
Teses & 0 & 0 & 2 & 4 & 3 \\
Trabalhos e pôsteres de eventos & 30 & 46 & 35 & 64 & 30 \\
\hline
\end{tabular}
Fonte: Elaborada pelos autores.

É possível indicar, a partir dos dados, que a temática do planejamento de ensino e seus elementos vem sendo pouco discutida na área de Ensino de Ciências. Uma possível justificativa para esta constatação é, por um lado, o amplo leque de temáticas e focos de pesquisa que vem sendo investigado nos últimos anos. Como destacado pelo documento da área de Ensino (Araújo-Jorge, Borba, \& Sovierzoski, 2016), tem se observado um crescimento no número de programas de pós-graduação, bem como da produção de publicações. O documento destaca que: 
Em novembro de 2016 a Área de Ensino totalizava 148 Programas, presente em todas as regiões do país. A segunda mais densa Área da Grande Área Multidisciplinar, e a maior em percentual de cursos de Mestrado Profissional (51\%). Em dezembro de 2016 dez novos mestrados foram recomentados pela CAPES (2 acadêmicos e 8 profissionais), que ainda não integram a presente análise, mas que expandem a Área para 158 PPG (Araújo-Jorge, Borba, \& Sovierzoski, 2016, p. 4).

No entanto, Villani, Dias e Valadares (2010), ao analisarem o desenvolvimento da pesquisa em Ensino de Ciências no Brasil, discutem que o processo de institucionalização da área pode ser dividido em três fases: o nascimento e sua configuração inicial; seu processo de amadurecimento; e surgimento de um grande número de linhas de pesquisa. Em cada uma dessas fases, segundo os autores, observou-se ênfase em algumas temáticas, tais como: concepções alternativas e mudança conceitual, o papel da História e Filosofia da Ciência, estudos envolvendo as diferenças entres professores e pesquisadores. Dessa forma, é possível afirmar que, ao longo do desenvolvimento das pesquisas da área, algumas temáticas foram mais amplamente discutidas e se consolidaram historicamente. Quando comparada a essas tradicionais linhas de pesquisa, é possível indicar que a temática do planejamento de ensino não guarda as mesmas proporções em termos de número de trabalhos publicados e, por isso, trata-se de uma temática menos investigada pela comunidade.

Em termos qualitativos, a análise dos trabalhos selecionados se focou na investigação das definições e/ou referenciais citados pelos autores. Os resultados são discutidos caso a caso a seguir. Porém, cabe ressaltar que em apenas 10,4\% do número total de trabalhos selecionados se encontrou alguma definição ou mesmo referenciais que tratassem dos termos investigados.

O termo mais utilizado nas buscas foi estratégia, com 35\% do número total de trabalhos, seguido do termo metodologia $(27,6 \%)$, recurso $(26,8 \%)$, método $(8,9 \%)$ e técnica (1,70\%). Como o termo estratégia foi o mais citado, isso pode indicar que este seja o termo que mais vem sendo adotado e, assim, vem se consolidando entre pesquisadores da área quando se referem ao planejamento do professor. No entanto, pode indicar, também, um problema conceitual e terminológico, já que em muitos trabalhos há o entendimento de que qualquer atividade possa vir a ser entendida como estratégia de ensino.

Apenas $17,7 \%$ dos trabalhos que utilizavam o termo estratégia apresentavam definições e referenciais teóricos. Entre os que traziam referenciais, notou-se a presença dos seguintes autores: Beluce (2012); Luckesi (1994); Manzini (2010); Masetto (2012); Morin (2005); Petrucci e Batiston (2006); e Sant’Anna e Menegolla (2011).

Os autores supracitados, no geral, entendem estratégias como ordenações sequenciadas de procedimentos, como meios utilizados pelo professor para articular o processo de ensino, e como os passos seguidos pelo professor posteriormente à definição dos objetivos. Nessa acepção, as estratégias didáticas são viabilizadoras dos objetivos pretendidos e entendidas como ações intencionadas e planejadas, como conjunto de 
ações elaboradas com vistas a um objetivo, como conjuntos de meios utilizados pelo professor para facilitar a aprendizagem dos estudantes e, finalmente, como ações que ocorrem durante o processo de ensino e avaliação.

Os trabalhos analisados destacaram e classificaram como sendo estratégias de ensino: resolução de exercícios e problemas; atividades em dupla/grupo; estudo dirigido; análise de documentos, filmes, vídeos e simulações; debates; atividades práticas; ilustrações; produção e discussão de textos; demonstrações; atividade extraclasse; diálogos; elaboração de modelos didáticos; seminários; aula expositiva; utilização de softwares; e o uso de mapas conceituais. Tal classificação concorda com a classificação dada por Farias e colaboradores (2011) para o termo estratégia. Os autores definem as estratégias como andaimes didáticos que permitem a interação entre professor, aluno e o conhecimento e consideram como estratégias, por exemplo, seminários, júri simulado, debates, exposições orais e tantas outras.

O segundo termo mais discutido nos trabalhos analisados foi metodologia, a qual apareceu em 111 trabalhos. Porém, apenas 5,40\% desses trabalhos apresentavam definições e referências. Os referenciais adotados foram Manfredi (1993) e Haydt (2006). Os trabalhos consideravam metodologia de ensino como formas diferenciadas do conteúdo, como capacidade de utilizar diferentes estratégias para o processo de ensino e aprendizagem e como caminho para se atingir um objetivo.

Em apenas um trabalho observou-se uma definição para o termo, porém não havia referencial em que o autor se baseasse. Nesse trabalho, em específico, considerouse metodologia como um procedimento didático utilizado pelos professores com o intuito de criar condições favoráveis ao processo de ensino e aprendizagem.

Ao analisar o que os autores classificaram como metodologias de ensino, a seguinte lista foi identificada: utilização de vídeos, músicas, blogs e jogos, além de seminários e oficinas. Em outros trabalhos, porém, foram consideradas metodologias: o ensino baseado em problemas, o ensino por investigação e os três momentos pedagógicos. Nota-se que o primeiro grupo de autores possui uma concepção sobre metodologia mais próxima à ideia de ações desenvolvidas durante o ensino e, pode-se dizer, então, que mais próxima da concepção de estratégia dada por Farias e colaboradores (2011). Já o segundo grupo de autores entendem metodologia relacionada às ideias dos professores acerca do processo de ensino e aprendizagem, em outras palavras, suas concepções sobre o que é aprender e de como o ensino deve ser conduzido.

O termo recurso foi o terceiro mais discutido, mas o que apresentou menores divergências quanto à classificação. Foram classificados como recursos didáticos: jogos; simuladores; materiais de divulgação científica; livros; datashow; lousa e giz; e outros objetos.

Apenas $8(7,40 \%)$ dos 108 trabalhos apresentavam definição para recurso didático. Um dos trabalhos fez uso do referencial Castoldi e Polinarski (2009), que definem os recursos didáticos como os materiais que auxiliam a aprendizagem dos estudantes. Outros trabalhos citaram referenciais como Sant'Anna e Sant'Anna (2004), Libâneo 
(2013), Zabala (1998) e Góes (2002). Resumidamente, esses autores entendem recursos didáticos como conjuntos de meios materiais que auxiliam o professor na interação com os alunos; como instrumentos de aprendizagem; e como meios que ajudam os professores a responder aos problemas concretos do processo de ensino e aprendizagem.

O termo método de ensino foi utilizado em 36 trabalhos. Dentre eles, apenas 3 $(8,33 \%)$ trabalhos continham a definição referenciada para o termo. O termo método foi definido como um "caminho que conduz a um fim". Tal termo foi o que mais apresentou divergências e conflitos quanto à classificação e definição. Em um mesmo trabalho, ora se utilizava estratégia como sinônimo de método, ora método como sinônimo de metodologia. Dentre todos os trabalhos, $6 \%$ usaram o termo sem qualquer diferenciação ou definição, sem se observar nenhuma associação ou qualquer tipo de referência que permitisse a equivalência dos termos. Acredita-se que isso se deva ao fato de a maioria dos trabalhos ter utilizado os termos sem aportes teóricos, ou seja, apenas por sua popularização, experiência dos autores ou mesmo conhecimento de senso comum.

O termo menos utilizado nos trabalhos investigados foi técnica. Tal fato pode indicar que esse é o termo menos popular na área de Ensino de Ciências. Analisou-se 7 trabalhos que discutiam as técnicas de ensino, no entanto, em nenhum deles havia qualquer definição ou a classificação acerca do que se estava considerando como técnica.

Em síntese, observou-se que há conflitos terminológicos e que, na grande maioria dos trabalhos, os termos dos elementos do planejamento têm sido utilizados devido à sua popularização e, logo, sem sua vinculação a referenciais teóricos do campo de estudo. Dessa forma, torna-se evidente a necessidade de conduzir pesquisas que busquem, de um lado, a proposição de equivalência terminológica e, de outro, definições para esses termos.

Baseado nisso, na seção seguinte, são apresentadas reflexões críticas e propostas de definições para esses cinco termos (metodologia, método, estratégia, técnica e recurso) no sentido de contribuir para o avanço de pesquisas dentro dessa temática na área de Ensino de Ciências.

\section{Proposição de definições para os termos do planejamento de ensino}

Objetiva-se, nesta seção, apresentar uma reflexão crítica acerca das definições e acepções que têm sido utilizadas para designar os elementos do planejamento de ensino. Para a consecução de tal objetivo, conforme discutido anteriormente, buscouse a origem etimológica dos termos, seu significado dicionarizado e, por fim, o sentido que os termos têm assumido no contexto mais amplo e, especificamente, no contexto da educação.

O primeiro termo a ser discutido é o termo estratégia. Sua origem etimológica vem das palavras gregas stratos e agein, que significam, respectivamente, exército e comandar. Assim, a definição primeira do termo remete à ação de comandar exércitos (Martins, 1984). 
O significado dicionarizado da palavra também faz referência à terminologia militar e traz a seguinte definição:

S. f. 1. Arte militar de planejar e executar movimentos e operações de tropas, navios e/ ou aviões, visando a alcançar ou manter posições relativas e potenciais bélicos favoráveis a futuras ações táticas sobre determinados objetivos. 2. Arte militar de escolher onde, quando e com que travar um combate ou uma batalha. [Cf., nesta acepç., tática (2).] 3. P. ext. Arte de aplicar os meios disponíveis com vista à consecução de objetivos específicos. 4. P. ext. Arte de explorar condições favoráveis com o fim de alcançar objetivos específicos. 5. Fig. Fam. V. estratagema (2) (Ferreira, 2009, p. 835).

Martins (1984), ainda no contexto militar, discute que uma estratégia tem de ser flexível e conter soluções alternativas igualmente viáveis e capazes de conduzir aos fins pretendidos, permitindo correções exigidas no decorrer dos acontecimentos.

$\mathrm{Na}$ área educacional, variadas definições são observadas para o termo. Farias e colaboradores (2011), como já discutido, definem estratégias como andaimes didáticos que permitem e sustentam a interação entre aluno, professor e o conhecimento. Os autores justificam essa definição devido ao fato de as estratégias, analogamente aos andaimes da construção civil, serem necessárias para organizar os materiais e permitir uma atuação docente segura. Henning (1998) entende estratégia como uma forma de acionar o processo de instrução, visando atingir desempenhos científicos e possibilitando que os propósitos da instrução sejam alcançados. Delizoicov e Angotti (1992), por sua vez, concebem que as técnicas e as estratégias de ensino não se constituem em metodologias de ensino, porém fazem partes delas.

Assim, para um entendimento mais adequado do significado de estratégia, um caminho que se apresenta bastante frutífero é o de apresentar suas diferenças e aproximações do termo metodologia.

A definição etimológica do termo metodologia advém das palavras gregas methodos, ou seja, meta que significa objetivo, finalidade; hodos que significa caminho, intermediação; e logia que quer dizer conhecimento, estudo.

No dicionário, metodologia está assim definida:

S. f. 1. A arte de dirigir o espírito na investigação da verdade. 2. Filos. Estudo dos métodos e, especialmente, dos métodos das ciências: metodologia das ciências naturais. [Cf., nesta acepç., epistemologia e teoria do conhecimento.] 3. Liter. Conjunto de técnicas e processos utilizados para ultrapassar a subjetividade do autor e atingir a obra literária (Ferreira, 2009, p. 1322).

Já no contexto escolar, Araujo (2012) designa metodologia como o elemento estruturador que direciona o que pode e precisa ser feito, ou seja, uma dimensão orientadora e prescritiva do fazer pedagógico. Ademais, o autor descreve a metodologia como tendo uma dimensão teórico-prática ou, em outras palavras, uma metodologia não pode ser praticada sem ser pensada e, também, não pode ser pensada fora do contexto da prática. Amaral (2006) concorda com o entendimento segundo o qual a metodologia é entendida como a dimensão estruturadora do planejamento de ensino, responsável, de 
certo modo, por estruturar, moldar, estratégias, recursos e o processo de avaliação.

Contrariamente, Leal (2005) afirma que metodologia é o "conjunto de métodos aplicados à situação didático-pedagógica” (p. 4) e complementa que, para evitar a mesmice metodológica, o professor precisa reconhecer que "há uma diversidade metodológica que pode ser trabalhada em sala de aula e/ou numa situação didático-pedagógica” (p. 5). A partir desse entendimento, a autora classifica como metodologias de ensino: exposição; trabalhos em grupos; estudos dirigidos; tarefas individuais; pesquisas; experiências de campo; júri simulado; aulas expositivas; ensino individualizado; entre outros.

Interessante notar que esse último entendimento para metodologia está bastante próximo ao de estratégia de ensino e contrapõe o entendimento de metodologia como dimensão estruturadora do planejamento.

A compreensão de Fisher (1978) para o termo metodologia, por seu turno, relaciona-se à ideia da articulação entre uma teoria de compreensão e interpretação da realidade e uma prática específica. Nesse sentido, pode-se afirmar que a dimensão metodológica do planejamento, no âmbito do Ensino de Ciências, relaciona-se com o seguinte: uma fundamentação teórica sobre o agir sistematicamente nas escolas, abarcando as concepções psicológicas e pedagógicas de fundo acerca do processo de ensino e aprendizagem; os objetivos da educação formal; uma visão de natureza da ciência; e os papéis de professores e alunos no processo educativo.

A metodologia de ensino é, por consequência, a responsável por moldar e orientar os demais elementos do planejamento do professor. Concepção esta que se apresenta em consonância com as definições de Araujo (2012) e Amaral (2006), porém contrária à perspectiva apresentada por Leal (2005).

Com efeito, a partir da ampla revisão realizada, a acepção de metodologia que se defende neste trabalho como mais adequada é aquela em que seu sentido está próximo ao de sua origem etimológica, ou seja, relacionada com o significado de caminho, no sentido de estudo dos métodos. Entende-se, nessa perspectiva, que um professor não muda suas concepções de fundo em diferentes momentos e atividades no contexto da sala de aula, mas possui uma certa concepção metodológica, explícita ou implícita, que orienta de certo modo o desenvolvimento de suas ações. Logo, um professor não utilizaria diferentes metodologias para ensinar determinado tópico, mas possui uma determinada tendência metodológica que orienta suas ações em sala de aula.

A partir dessa definição, é possível classificar como metodologias, no âmbito particular do Ensino de Ciências: o Ensino por Transmissão (EPT) (Cachapuz, Praia, \& Jorge, 2002); o Ensino por Descoberta (EPD) (Cachapuz, Praia, \& Jorge, 2002); o Ensino por Investigação (Carvalho, 2013); os Três Momentos Pedagógicos (Delizoicov, \& Angotti, 1992); a Abordagem CTS (Santos, \& Mortimer, 2002); a Aprendizagem Baseada em Problemas (PBL, do inglês, Problem-Based Learning) (Ribeiro, 2005), entre outras.

Após a definição do que se considera como metodologia, pretende-se discutir suas diferenças em relação às estratégias. Vieira e Vieira (2005) utilizam o termo estratégia 
de ensino como um conjunto de ações orientadas do professor a fim de se promover o desenvolvimento de competências nos alunos. Anastasiou e Alves (2004), por sua vez, entendem estratégia como a aplicação de diferentes meios para se alcançar uma aprendizagem efetiva.

Interessante notar que, para esses autores, as estratégias se relacionam às ações didáticas desenvolvidas pelo professor a fim de atingir finalidades e objetivos. Esse é o mesmo entendimento de Farias e colaboradores (2011) e Henning (1998). Essa perspectiva corrobora seu significado dicionarizado e também a proposição de Martins (1984) para o termo estratégia, o qual a define como soluções capazes de conduzir aos objetivos pretendidos.

Nesse entendimento, propõe-se que as estratégias sejam compreendidas como um conjunto de ações intencionais e planejadas que visam à consecução dos objetivos de aprendizagem delimitados. São, por isso, intrinsecamente flexíveis e igualmente condicionadas pelas concepções de fundo do professor. Ademais, pode-se dizer que, no âmbito formal do planejamento, as estratégias são escolhidas a partir da definição dos objetivos de aprendizagem. Logo, elas não são sinônimos de metodologias.

Sobre o caráter flexível das estratégias, Amaral (2006) aponta:

Por exemplo, por mais que nos esforcemos, ao utilizar a aula expositiva para a problematização de um tema, ou para desenvolver o pensamento crítico e divergente nos alunos, jamais ela alcançará a eficácia de um debate ou de uma simulação. Vale, também, o raciocínio inverso: se nossa intenção for o fechamento final de um assunto, ou a transmissão rigorosa de noções e conceitos, o debate nunca será tão adequado quanto uma aula expositiva (Amaral, 2006, p. 4).

O autor alega, também, que, apesar de as estratégias serem moldadas a partir de determinada metodologia de ensino, só é possível alterar suas características secundárias, uma vez que, se houver uma mudança em suas características primárias, elas deixam de ter as propriedades que as definem e passam a constituir outras estratégias de ensino.

Outro aspecto importante sobre as estratégias é de que elas não possuem uma relação biunívoca com os objetivos, uma vez que, em alguns casos, pode-se requerer mais de uma estratégia de ensino para a consecução de determinado objetivo de aprendizagem. Por outro lado, uma mesma estratégia de ensino pode ser utilizada em momentos diferentes para se atingir objetivos variados (Sánchez Blanco, \& Valcárcel Perez, 1993). A intencionalidade da estratégia será determinada pela fase da sequência de ensino (abertura, desenvolvimento, aplicação ou conclusão) e pela abordagem metodológica adotada.

A partir da definição e das características apresentadas, pode-se classificar como estratégias de Ensino de Ciências: a utilização de experimentação (Giordan, 1999); o uso de mapas conceituais (Moreira, 2006); a aplicação de estudos de casos (Sá, Francisco, \& Queiroz, 2007); o uso de jogos didáticos (Cunha, 2012); a utilização de modelos, analogias e metáforas (Monteiro, \& Justi, 2000); o uso da História e Filosofia da Ciência (Loguercio, \& Del Pino, 2006); a aprendizagem centrada em eventos (ACE) (Cruz, 
2001); e muitas outras.

O termo técnica é, agora, analisado e discutido criticamente. Sua origem etimológica vem das palavras gregas $\tau \dot{x} \chi v \eta$ e téchne, que, em geral, referem-se a toda série de regras por meio das quais se alcança algo.

A busca pelo significado dicionarizado do termo retornou a seguinte definição:

S. f. 1. A parte material ou conjunto de processos de uma arte: técnica cirúrgica, técnica jurídica. 2. Maneira ou jeito ou habilidade especial de executar ou fazer algo: este aluno tem uma técnica muito sua de estudar. 3. Prática (4). [Cf. tecnologia.] (Ferreira, 2009, p. 1925).

No contexto educacional, Araujo (2012) define técnicas de ensino como as atividades desenvolvidas nas escolas e que são, portanto, um modo de fazer que contém diretrizes e orientações que objetivam à aprendizagem dos estudantes.

Anastasiou e Alves (2004) definem as técnicas de ensino como conjuntos de processos de uma arte, maneiras ou jeitos especiais de fazer algo. As autoras entendem que esse termo pode ser entendido como sinônimo do termo estratégia. No entanto, elas optam por fazer uso do termo estratégia de ensino por compararem o trabalho do professor ao de um estrategista, ou seja, um trabalho que deve levar em conta os condicionantes da realidade de cada escola. Da mesma forma, Delizoicov e Angotti (1992) utilizam os termos como sinônimos, porém optam, sem qualquer justificativa, por adotarem o termo técnica.

A partir dessas definições e acepções, advoga-se que os termos estratégias e técnicas de ensino, no contexto da Didática, não se confundem com a definição de metodologia, mas podem ser entendidas como conjunto de ações planejadas pelo professor a fim de se atingir determinado objetivo de aprendizagem. Concorda-se, portanto, com Anastasiou e Alves (2004) e Delizoicov e Angotti (1992) e entende-se que os termos técnica e estratégia podem ser considerados como sinônimos por possuírem acepções próximas no contexto da Didática.

No entanto, neste trabalho, advoga-se, no âmbito do planejamento didáticopedagógico, pela adoção do termo estratégia em detrimento do termo técnica, pelas seguintes razões:

1) A própria definição do termo defendida pela maioria dos autores e por seu significado dicionarizado, ou seja, técnica é uma "maneira ou jeito ou habilidade especial de executar ou fazer algo", "modo específico de fazer algo", "maneiras ou jeitos especiais de fazer algo". Esse tipo de significado pode sugerir que há um modo fechado, correto e fixo de se fazer algo e, portanto, que a técnica é sempre pronta e acabada, podendo ser utilizada em qualquer contexto da mesma maneira e obter sempre o mesmo resultado. Nesse sentido, utilizar o termo técnica no contexto do planejamento pode conduzir à concepção de que as técnicas utilizadas para o ensino possuem as mesmas características das técnicas de natação, por exemplo, em que o nadador tem de segui-las à risca, haja vista existir uma maneira correta de se executar uma ação com o intuito de aproximá- 
la de um ideal padronizado;

2) A associação do termo técnica com o modelo conceitual da docência apresentado na literatura especializada como modelo da racionalidade técnica (Bego, 2016). Essa associação pode remeter às práticas pedagógicas da amplamente refutada pedagogia tecnicista, a qual é sobejamente insuficiente e inadequada para abarcar tanto o trabalho docente quanto a complexidade do ambiente escolar;

3) O pequeno número de trabalhos publicados na área que utilizam o termo. $\mathrm{O}$ resultado da revisão sistemática realizada neste trabalho apontou que o termo técnica tem a menor frequência de utilização, sugerindo ser, recentemente, o menos popular na área. Contrariamente, o termo estratégia foi o que apareceu com maior frequência de utilização;

4) É possível comparar o trabalho do professor ao de um estrategista, ou seja, um trabalho que envolve estudo, seleção, organização e proposições de ações flexíveis que visam alcançar determinado objetivo de aprendizagem. Porém, essas ações precisam ser adaptadas às situações reais de ensino, sempre complexas, multifacetadas e singulares (Anastasiou, \& Alves, 2004; Bego, 2016).

Finalmente, discute-se o termo método, o qual apresentou maior número de conflitos conceituais e terminológicos nos trabalhos analisados. A origem etimológica da palavra vem do grego methodos, de meta (objetivo, finalidade) e hodos (caminho), ou seja, caminho a seguir para alcançar um fim.

A busca pelo termo no dicionário retorna a seguinte definição:

S. m. 1. Caminho pelo qual se atinge um objetivo. 2. Programa que regula previamente uma série de operações que se devem realizar, apontando erros evitáveis, em vista de um resultado determinado. 3. Processo ou técnica de ensino: método direto. 4. Modo de proceder; maneira de agir; meio. 5. V. meio (8). 6. Tratamento elementar. 7. Fig. Prudência, circunspecção; modo judicioso de proceder; ordem: Age sempre com método (Ferreira, 2009, p. 1322).

$\mathrm{Na}$ literatura mais geral, encontrou-se que método é o conjunto das atividades sistemáticas que permite alcançar um objetivo (Marconi, \& Lakatos, 2011). Já, no contexto da Didática, Veiga e colaboradores (1992, grifos nossos) trazem a seguinte definição para o termo: "[...] o método traz, dentro de si, a ideia de uma direção com a finalidade de alcançar um propósito, não se tratando, porém, de uma construção qualquer, mas daquela que leva de forma mais segura à consecução de um propósito buscado" (p.84). Os autores elencam três métodos de ensino, quais sejam, o método tradicional, o método intuitivo e o método ativo. Tais métodos possuem características distintas quanto ao papel do aluno e à forma de conceber o processo de ensino e aprendizagem.

Nessa mesma direção, Farias e colaboradores (2011) definem método como conjunto composto por pressupostos, princípios e procedimentos que auxiliam o trabalho pedagógico, abrigando elementos conceituais e operacionais que permitem a 
concretização da prática educativa. Como se nota, para os autores, métodos e metodologias são termos muito próximos conceitualmente.

Amaral (2006) define método como caminho que leva a um determinado fim. Porém, é possível notar que, para o autor, metodologia e método de ensino não são sinônimos, uma vez que "[...] os métodos são, pois, os meios, os caminhos, no processo de ensino e aprendizagem, determinando o próprio teor da mensagem que está sendo veiculada" (p.5). Adicionalmente, o autor afirma que "[...] os métodos concretizam e articulam sua forma de utilização [referindo-se a outros elementos do planejamento], compondo coerentemente a correspondente visão metodológica de ensino" (p. 8).

Diante do exposto, pode-se inferir que método não é sinônimo de estratégia e técnica, pois ele as abrange. Um método de ensino se caracteriza por um conjunto de atividades articuladas que compõem um caminho que leva, de forma mais segura, à consecução de um propósito de ensino. Por isso, o método é inerentemente formado por pressupostos e princípios que guiam a atividade do professor em sala de aula, configurando um caminho direcionado. Por esse entendimento, um método de ensino não teria a característica de flexibilidade e complementariedade inerente às estratégias.

Um outro aspecto importante a ser discutido se refere à relação entre método e metodologia. A partir dos entendimentos de Farias e colaboradores (2011) e Veiga e colaboradores (1992), poder-se-ia assumir os termos método e metodologia como sinônimos. Todavia, com base nas considerações de Amaral (2006), de Fisher (1987) e da própria origem etimológica do termo metodologia, é possível identificar uma importante diferença entre metodologia e método.

A palavra metodologia, constituída pelo sufixo "logia", relaciona-se fortemente à dimensão de estudo dos métodos, isto é, relacionada à ideia de uma teoria de compreensão e interpretação da realidade que irá orientar e fundamentar a prática pedagógica. Por sua vez, o termo método, como apontado por Amaral (2006), comporia a dimensão concreta do caminho proposto e percorrido pelo professor, composto pela articulação e estruturação das estratégias e recursos em uma dada situação concreta de ensino.

Dessa forma, em síntese, propõe-se que método não se confunde com metodologia, uma vez que a metodologia está relacionada ao plano teórico acerca das concepções de fundo sobre o processo de ensino e aprendizagem. A metodologia se relaciona ao caráter social da área em termos das proposições de abordagens para o ensino pautadas em determinadas concepções, princípios e pressupostos. $\mathrm{O}$ método, porém, possui caráter mais concreto e envolve a aplicação ajustada de uma abordagem metodológica. Logo, o método diz respeito à adaptação e reelaboração de uma perspectiva metodológica de ensino realizada por um professor em um dado contexto concreto. Ao contrário da metodologia, o método apresenta marcadamente um caráter personalizado.

A Figura 1 apresenta um esquema das inter-relações entre conceitos discutidos até aqui. Tal esquema destaca as características e as relações estabelecidas entre os elementos do planejamento e a prática pedagógica, segundo as definições propostas neste trabalho. 


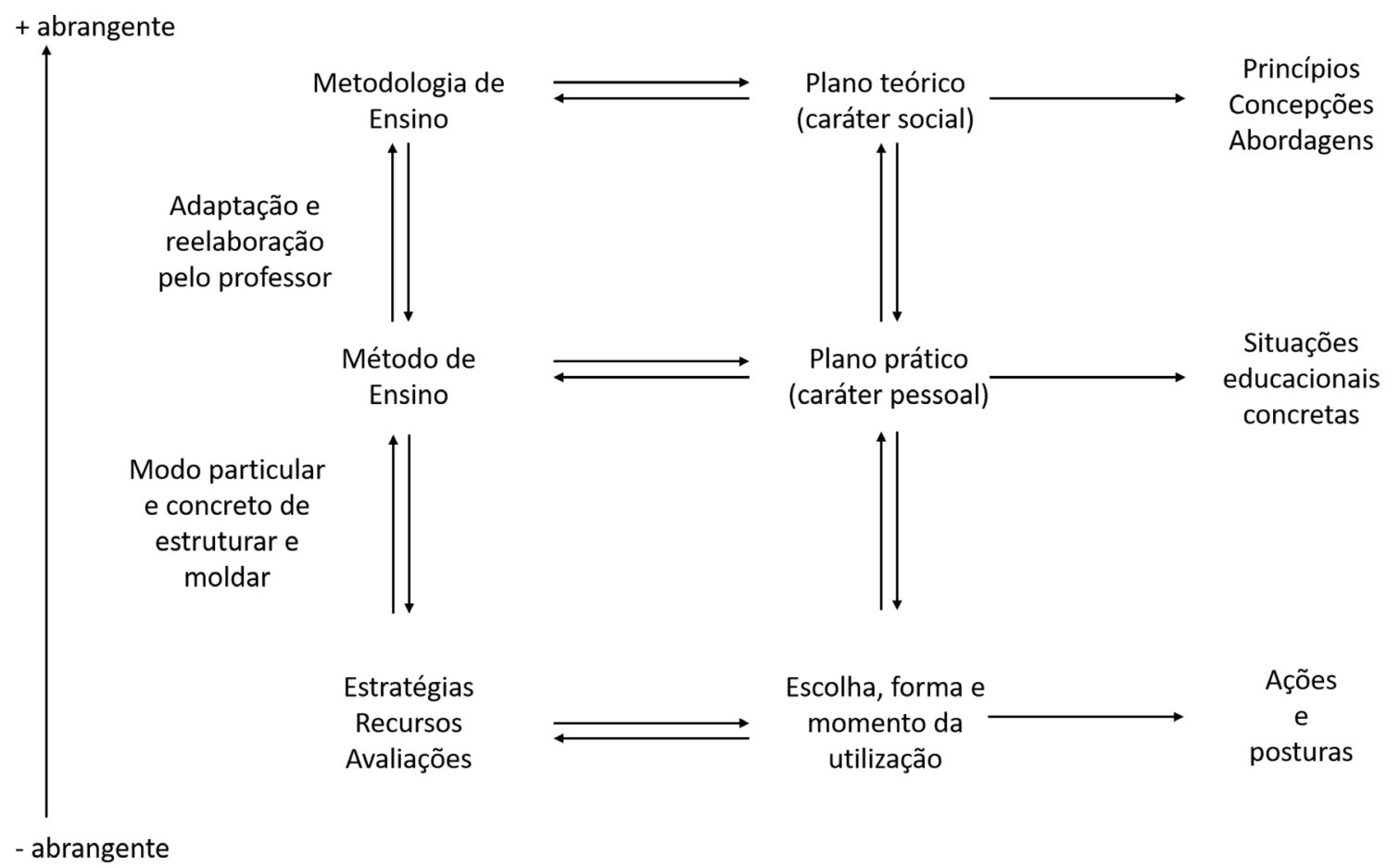

Figura 1. Características e relações entre os elementos do planejamento e a prática pedagógica do professor

Fonte: Elaborada pelos autores.

$\mathrm{Na}$ Figura 1, as setas duplas indicam a inter-relação entre os elementos do planejamento e representam as influências das adaptações que esses elementos sofrem diante das tradições e das condições práticas em que se encontram. Cabe sublinhar que as setas não indicam as intensidades das relações, mas representam o movimento de influência e interdependência entre os elementos que compõem o planejamento de ensino.

Como se nota, a metodologia de ensino está em um plano teórico e se relaciona com as estratégias no sentido de orientar teoricamente os critérios de sua seleção e organização. Já o método de ensino está em um plano prático do planejamento, pois se caracteriza por ser um modo particular e concreto de cada professor de moldar e estruturar estratégias e os recursos didáticos. Destaca-se, também, a metodologia como sendo o elemento mais abrangente do planejamento e que todos os elementos (metodologia, método, estratégias, recursos e avaliação) estão interligados.

Vale ressaltar, ainda, que há uma tensão dialética entre o plano teórico e o plano prático. O primeiro tem um caráter social e o segundo tem um caráter pessoal, uma vez que a abordagem metodológica de ensino orienta a escolha e estruturação dos demais elementos do planejamento. Todavia, as proposições teóricas para abordagens metodológicas de ensino são, também, influenciadas pelas tradições que se materializam no campo da prática. Assim, teoria e prática estão constantemente inter-relacionadas.

Com base em todas essas considerações, finalmente, o último termo discutido é 
recurso. A origem etimológica do termo vem do latim recursus, cujo significado é fazer de novo um caminho. Seu significado dicionarizado acompanha algumas definições, dentre as quais:

S. m. 1. Ato ou efeito de recorrer. 2. Auxílio, ajuda, socorro, proteção. 3. Meio, expediente: usou todos os recursos disponíveis. 4. Meio pecuniário; numerário: Viu-se de repente, sem recursos para enfrentar os gastos. 5. Meio para resolver um problema; remédio, solução. 6. Jur. Meio de provocar, na mesma instância ou na superior, a reforma ou a modificação de uma sentença judicial desfavorável. 7. Bras. N. E. V. casa de tolerância. $\sim$ V. recursos (Ferreira, 2009, p. 1714).

Como se nota, essa definição remete, principalmente, ao contexto do direito, em que um recurso é utilizado com o objetivo de pedir a mudança de uma sentença desfavorável em determinada instância.

No contexto educacional, utiliza-se com frequência o termo recurso didático. Veiga e colaboradores (1992), por exemplo, discutem que:

[...] os recursos disponíveis para o desenvolvimento do trabalho didático tendem a ser considerados como simples instrumentos de ilustração das aulas, reduzindo-se dessa forma a equipamentos e objetos, muitas vezes até inadequados aos objetivos e conteúdos estudados (Veiga et al.,1992, p. 41).

Aparecem, no entanto, outros termos como: materiais de aprendizagem (Sánchez Blanco, \& Valcárcel Perez, 1993) e materiais curriculares (Zabala, 1998). Zabala (1998) define materiais curriculares como meios que auxiliam os professores a resolver problemas das diferentes etapas dos processos de planejamento, execução e avaliação. Para o autor, materiais curriculares e recursos didáticos são sinônimos.

Farias e colaboradores (2011) definem recursos didáticos como meios, materiais e instrumentos que dão suporte à ação docente. Amaral (2006), por sua vez, define-os como veículos de algum conteúdo.

Todas essas definições indicam que não há muitas divergências e disparidades nas acepções propostas pelos autores e no significado dicionarizado do termo, exceto no contexto do Direito. Tal fato corrobora os resultados obtidos pela revisão sistemática apresentada na seção anterior. Nota-se que as definições apresentadas retornam a um objeto e a meios físicos que suportam a realização das atividades. Dessa forma, a depender dos referenciais utilizados e, a partir de uma perspectiva mais geral, esses termos podem ser considerados como sinônimos.

No entanto, há alguns autores que optam por fazer uma distinção entre os termos recursos didáticos e materiais de aprendizagem ou curriculares.

No entendimento desses autores, os recursos didáticos são objetos ou meios disponíveis utilizados como suporte para a realização das atividades (Sanmartí, 2002; Sánchez Blanco, \& Valcárcel Perez, 1993). Concordando-se com esses autores, propõese que recursos didáticos podem ser entendidos como suportes físicos que são veículos de algum conteúdo e auxiliam no desenvolvimento das estratégias didáticas, mas que não são produzidos necessariamente pelos professores. Consequentemente, segundo 
essa classificação, podem ser considerados recursos didáticos: lousa, giz, datashow, retroprojetor, tabela periódica, revistas, jornais, computador, aplicativos, vídeo, filme, reagentes e vidrarias de laboratório, entre outros.

Por sua vez, os materiais de aprendizagem (curriculares) são entendidos como materiais preparados por professor e/ou alunos para a realização de atividades específicas e localizadas da sala de aula, tais como: um mapa conceitual, um roteiro experimental, listas de exercícios, apresentações de slides, entre outros (Sanmartí, 2002; Sánchez Blanco, \& Valcárcel Perez, 1993). Embora não sejam sinônimos, nesse sentido, tanto os recursos didáticos como os materiais de aprendizagem se relacionam diretamente com as estratégias didáticas.

A Figura 2 apresenta a síntese e as sistematização das definições propostas para os elementos constituintes do planejamento de ensino.

\begin{tabular}{|l|l|l|l|}
\hline $\begin{array}{l}\text { Elementos do } \\
\text { planejamento }\end{array}$ & Definição do termo & Características & Exemplos \\
\hline Metodologia & $\begin{array}{l}\text { É toda teoria sobre o } \\
\text { processo de ensino e } \\
\text { aprendizagem. Está } \\
\text { relacionada com as } \\
\text { concepções psicológicas } \\
\text { e pedagógicas de fundo } \\
\text { sobre aprendizagem, a } \\
\text { natureza da ciência, a } \\
\text { função da educação escolar } \\
\text { e os papéis do professor e } \\
\text { dos alunos em aula }\end{array}$ & $\begin{array}{l}\text { Abarca estratégias de } \\
\text { ensino e avaliação e } \\
\text { recursos. Situa-se em } \\
\text { um plano teórico e } \\
\text { social do planejamento } \\
\text { desenvolvido } \\
\text { pela comunidade } \\
\text { acadêmica. } \\
\text { Responsável por } \\
\text { moldar e orientar todos } \\
\text { os demais elementos } \\
\text { do planejamento }\end{array}$ & $\begin{array}{l}\text { EPT; EPD; Ensino } \\
\text { por Investigação; Três } \\
\text { momentos pedagógicos; } \\
\text { Abordagem CTS; PBL }\end{array}$ \\
\hline Estratégia & $\begin{array}{l}\text { Conjunto de ações } \\
\text { intencionadas e } \\
\text { planejadas do professor } \\
\text { para a consecução dos } \\
\text { objetivos de aprendizagem } \\
\text { propostos, ou seja, } \\
\text { trata-se do elemento do } \\
\text { planejamento responsável } \\
\text { pela consecução dos } \\
\text { objetivos }\end{array}$ & $\begin{array}{l}\text { É flexível, moldada a } \\
\text { partir de determinada } \\
\text { abordagem } \\
\text { metodológica de } \\
\text { ensino. É definida, } \\
\text { em geral, após a } \\
\text { delimitação dos } \\
\text { objetivos }\end{array}$ & $\begin{array}{l}\text { Experimentação; uso de } \\
\text { mapas conceituais; estudos } \\
\text { de casos; uso de jogos } \\
\text { didáticos; utilização de } \\
\text { modelos e analogias; uso } \\
\text { da História e Filosofia } \\
\text { da Ciência; exibição de } \\
\text { documentários e ficção } \\
\text { científica; ACE. }\end{array}$ \\
\hline $\begin{array}{l}\text { Conjunto de ações } \\
\text { planejadas pelo professor } \\
\text { objetivo pré-estabelecido } \\
\text { (Pode ser considerada } \\
\text { sinônimo de estratégia })\end{array}$ & $\begin{array}{l}\text { Opta-se pelo uso do } \\
\text { termo estratégia, por } \\
\text { esse termo se associar } \\
\text { ao tecnicismo, dentre } \\
\text { outras razões }\end{array}$ & $\begin{array}{l}\text { Os mesmos exemplos de } \\
\text { estratégia }\end{array}$ \\
\hline
\end{tabular}

Figura 2. Elementos do planejamento de ensino, suas definições, características e classificações (continua)

Fonte: Elaborada pelos autores. 


\begin{tabular}{|l|l|l|l|}
\hline $\begin{array}{l}\text { Elementos do } \\
\text { planejamento }\end{array}$ & Definição do termo & Características & Exemplos \\
\hline Método & $\begin{array}{l}\text { Conjunto formado por } \\
\text { estratégias e recursos } \\
\text { didáticos, resultado dos } \\
\text { ajustes e moldagens } \\
\text { sofridos em virtude de uma } \\
\text { concepção metodológica de } \\
\text { fundo e dos condicionantes } \\
\text { concretos de atuação } \\
\text { docente }\end{array}$ & $\begin{array}{l}\text { Muda em função do } \\
\text { ponto de vista e dos } \\
\text { propósitos do professor. } \\
\text { Está em um plano } \\
\text { prático e pessoal do } \\
\text { planejamento }\end{array}$ & $\begin{array}{l}\text { É específico para cada } \\
\text { planejamento em dada } \\
\text { realidade escolar }\end{array}$ \\
\hline Recursos & $\begin{array}{l}\text { São meios físicos que dão } \\
\text { suporte e são veículos de } \\
\text { algum conteúdo }\end{array}$ & $\begin{array}{l}\text { Dão suporte para o } \\
\text { desenvolvimento das } \\
\text { estratégias didáticas } \\
\text { e não são produzidos } \\
\text { necessariamente pelo } \\
\text { professor }\end{array}$ & $\begin{array}{l}\text { Lousa; giz; tabela } \\
\text { periódica; revistas; } \\
\text { jornais; datashow; } \\
\text { notebooks; internet; } \\
\text { vídeo; filme; vidrarias e } \\
\text { reagentes }\end{array}$ \\
\hline $\begin{array}{l}\text { Materiais de } \\
\text { aprendizagem }\end{array}$ & $\begin{array}{l}\text { Materiais preparados por } \\
\text { professor e/ou alunos para } \\
\text { a realização de atividades } \\
\text { específicas na sala de aula }\end{array}$ & $\begin{array}{l}\text { Elaborados por professor } \\
\text { e/ou alunos }\end{array}$ & $\begin{array}{l}\text { Um mapa conceitual; } \\
\text { um roteiro experimental; } \\
\text { uma lista de exercícios; } \\
\text { uma apresentação de } \\
\text { slides etc. }\end{array}$ \\
\hline
\end{tabular}

Figura 2. Elementos do planejamento de ensino, suas definições, características e classificações (continuação)

Fonte: Elaborada pelos autores.

Apresenta-se na Figura 3 um mapa conceitual que sintetiza as ideias e definições propostas neste trabalho, bem como as inter-relações e características de todos os elementos do planejamento de ensino.

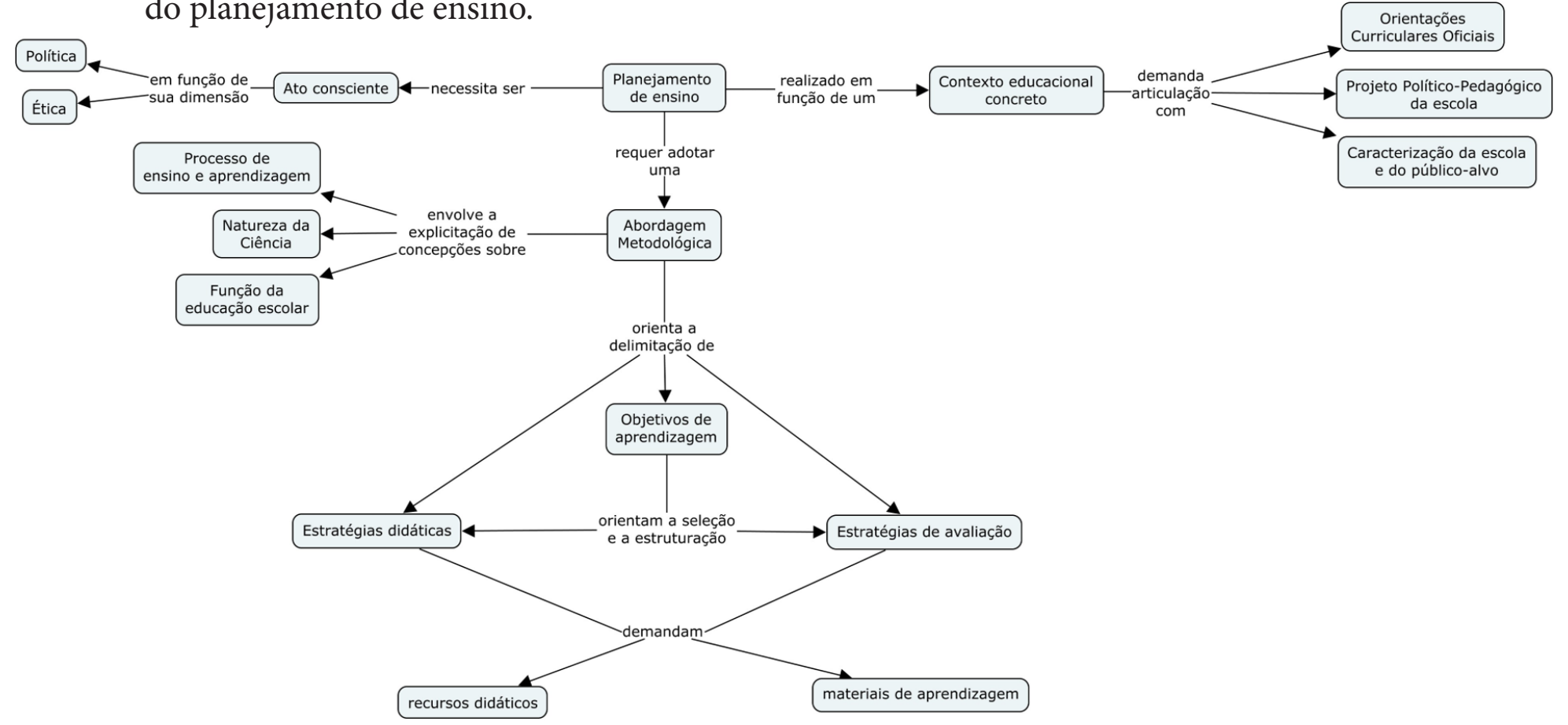

Figura 3. Mapa conceitual dos elementos constituintes do planejamento de ensino e sua estruturação Fonte: Elaborada pelos autores. 
Do ponto de vista do ato de planejar o Ensino de Ciências, defende-se que a abordagem metodológica orienta o processo instrucional e consiste em um elemento essencial do planejamento, o qual envolve a explicitação de concepções sobre o processo de ensino e aprendizagem, a natureza da ciência e a função da educação escolar.

Portanto, advoga-se que o planejamento de ensino, para além de uma atividade meramente burocrática e acrítica, é uma das dimensões nevrálgicas do trabalho docente uma vez que tem dimensão política e ética, em função de colocar em questão crenças, ideias e valores que orientam a prática pedagógica. Por isso, o planejamento de ensino necessita ser um ato consciente do professor, em que ele explicita e se conscientiza sobre a abordagem metodológica a ser adotada, a qual deve orientar a delimitação dos objetivos de aprendizagem, bem como a seleção e a estruturação das estratégias didáticas e de avaliação, recursos e materiais de aprendizagem demandados.

\section{Considerações finais}

Neste trabalho argumentou-se sobre a importância do planejamento e sobre a necessidade do ato de planejar o ensino ser um ato consciente do professor, em função de sua dimensão ética e política. Ademais, explicitou-se que o planejamento deve ocupar posição fundamental na prática pedagógica, uma vez que é responsável por orientar o trabalho do professor a fim de torná-lo uma contínua ação crítico-reflexiva.

Este trabalho envolveu, também, a realização de uma revisão sistemática que apontou a necessidade de uma definição mais criteriosa e embasada para os elementos do planejamento de ensino. Os elementos discutidos foram: estratégia, técnica, metodologia, método e recursos. Como constatado, no geral, os termos têm sido utilizados desvinculados de suas definições e de quaisquer referenciais teóricos. Além disso, observou-se incoerências e o uso indiscriminado dos termos como, por exemplo, considerar como equivalentes os termos metodologias e estratégias.

Diante de tais fatos, propôs-se definições para os elementos constituintes do planejamento de ensino. Para tanto, realizou-se uma busca pela origem etimológica dos termos, seu significado dicionarizado e a busca por seu sentido em um contexto mais amplo e, particularmente, no escopo da educação.

Segundo as proposições apresentadas, metodologia é o elemento mais abrangente do planejamento e envolve as concepções sobre a finalidade do processo de ensino e aprendizagem, a natureza da ciência e as características da educação escolar. Tal elemento molda e estrutura os demais, tais como estratégias, técnicas e recursos, em função de embasar a delimitação dos propósitos de ensino.

O termo estratégia foi definido como o conjunto de ações intencionais e planejadas pelo professor para a consecução de objetivos de aprendizagem. Como se argumentou, as estratégias são definidas após a delimitação dos objetivos e podem sofrer adaptações e ajustes a depender da abordagem metodológica adotada. Propôs-se que os termos estratégia e técnica possuem acepções próximas e podem ser considerados sinônimos, embora se tenha recomendado a utilização do primeiro termo em detrimento do 
segundo.

O termo método constitui-se, segundo o entendimento deste trabalho, como o conjunto formado por estratégias e recursos, resultado dos ajustes sofridos em virtude da metodologia assumida e das condições concretas de sala de aula. Assim, o método se encontra em um nível prático e pessoal do planejamento de ensino.

Os recursos didáticos são os meios físicos que dão suporte e veiculam dado conteúdo, não sendo produzidos necessariamente pelos professores. Ao contrário, os materiais de aprendizagem (ou curriculares) são preparados por professor e/ou alunos com vistas ao desenvolvimento de atividades didáticas específicas e localizadas.

Finalmente, ressalta-se que o movimento de proposição dos termos e suas definições foi realizado a partir de uma perspectiva teórica e, assim, não são proposições absolutas e inamovíveis. Posteriores estudos e aprofundamentos poderão ser realizados pela comunidade acadêmica a fim de se buscar um melhor entendimento acerca das dimensões, características e dos elementos do planejamento didático-pedagógico.

\section{Agradecimentos}

Os autores agradecem ao Ministério da Ciência, Tecnologia e Inovação e à Coordenação de Aperfeiçoamento de Pessoal de Nível Superior (CAPES) pelo financiamento da pesquisa.

\section{Referências}

Amaral, I. A. (2006). Metodologia do Ensino de Ciências como produção social. Recuperado de: http://docplayer.com.br/12841974-Metodologia-do-ensino-de-ciencias-comoproducao-social-versao-preliminar-ivan-amorosino-do-amaral-maio-de-2006.html

Anastasiou, L. G. C., \& Alves, L. P. (2004). Processos de ensinagem na universidade: Pressupostos para as estratégias de trabalho em aula. Joinville: Univille.

Araújo-Jorge, T. C., Borba, M. C., \& Sovierzoski, H. H. (2016). Considerações sobre classificação de periódicos. Recuperado de http://http://www.ppgcimes.propesp. ufpa.br/ARQUIVOS/documentos/DOCUMENTO_CRITERIOS_PERIODICOS_ ENSINO_2016.pdf

Araujo, J. C. S.(2012). Do quadro negro à lousa virtual: técnicas, tecnologia e tecnicismo. In I. P. A. Veiga (Org.), Técnicas de ensino: Novos tempos, novas configurações (pp. 1348). Campinas: Papirus.

Bardin, L. (2016). Análise de conteúdo. São Paulo: Edições 70.

Barradas Barata, R. de C. (2016). Dez coisas que você deveria saber sobre o Qualis. Revista Brasileira de Pós-Graduação. 13(30), 13-40. http://dx.doi.org/10.21713/23582332.2016.v13.947 
Bego, A. M. (2013). Trabalho escolar e trabalho docente. In A. M. Bego. Sistemas Apostilados de Ensino e Trabalho Docente: Estudo de caso com professores de Ciências e gestores de uma Rede Escolar Pública Municipal (pp. 93-127). (Tese de Doutorado em Educação para a Ciência). Faculdade de Ciências, Universidade Estadual Paulista "Júlio de Mesquita Filho". Bauru.

Bego, A. M. (2016). Políticas públicas e formação de professores sob a perspectiva da racionalidade comunicativa: da ingerência tecnocrata à construção da autonomia profissional. Educação \& Formação, 1(1), 3-24. https://doi.org/10.25053/edufor. v1i2.1864

Beluce, A. C. (2012). Estratégias de ensino e de aprendizagem e motivação em ambientes virtuais de aprendizagem. (Dissertação de Mestrado em Educação). Universidade Estadual de Londrina, Londrina.

Cachapuz, A., Praia, J., \& Jorge, M. (2002). Perspectivas de ensino: caracterização e evolução. Recuperado de https://edisciplinas.usp.br/pluginfile.php/1611805/mod_ resource/content/5/EPTeEPD.pdf

Carvalho, A. M. P. (2013). Ensino de Ciências por investigações: condições para a implementação em sala de aula. São Paulo: Cengage Learning.

Castoldi, R, \& Polinarski, C. A. (2009). A utilização de Recursos didático-pedagógicos na motivação da aprendizagem. In: I Simpósio Nacional de Ensino de Ciência e Tecnologia. (p.684). Ponta Grossa, PR.

Castro, P. A. P. P., Tucunduva, C. C., \& Arns, E. M. (2008). A importância do planejamento das aulas para organização do trabalho do professor em sua prática docente. Athena: Revista Científica de Educação, 10(10), 49-62.

Costa, A. B., \& Zoltowski, A. P. C. (2014). Como escrever um artigo de revisão de sistemática. In S. H. Koller, M. C. P. P. Couto \& J. V. Hohendorff. (Orgs.) Manual de Produção Científica (pp. 55-70). Porto Alegre, RS: Penso.

Cruz, S. M. S. C. S. (2001). Aprendizagem centrada em eventos: uma experiência com o enfoque Ciência, Tecnologia e Sociedade no ensino fundamental. (Tese de Doutorado em Educação). Centro de Ciências da Educação, Universidade Federal de Santa Catarina, Florianópolis.

Cunha, M. B. (2012). Jogos no ensino de química: considerações teóricas para utilização em sala de aula. Química Nova na Escola, 34(2), 92-98.

Delizoicov, D., \& Angotti, J. A. (1992). Metodologia do Ensino de Ciências. São Paulo: Cortez.

Farias, I. M. S., Sales, J. O. C. B., Braga, M. M. S. C., \& França, M. S. L. M. (2011). Didática e docência: aprendendo a profissão. Brasília: Liber Livro. 
Ferreira, A. B. H. (2009). Novo Dicionário Aurélio da língua portuguesa. 4. ed. Curitiba: Ed. Positivo.

Fischer, R. M. B. (1978). A Questão das Técnicas Didáticas: Uma proposta comprometida em lugar da decantada "neutralidade" das técnicas didático-pedagógicas. Ijuí: mimeo.

Giordan, M. (1999). O papel da Experimentação no Ensino de Ciências. Química Nova na Escola, 10, 43-49.

Góes, M. C. R. (2002). Relações entre desenvolvimento humano, deficiência e educação: contribuições da abordagem histórico-cultural. In M. K. Oliveira, D. T. R. Souza, \& T. C. Rego. (Orgs.), Psicologia, educação e as temáticas da vida contemporânea (95-114). São Paulo: Moderna.

Haydt, R. C. C. (2006). Curso de didática geral. São Paulo: Ática.

Henning, G. J. (1998). Metodologia do Ensino de Ciências. Porto Alegre: Mercado Aberto. Leal, R. B. (2005). Planejamento de ensino: peculiaridades significativas. Revista Iberoamericana de Educatión, 37(3), 1-6. https://doi.org/10.35362/rie3732705

Libâneo, J.C. (2013). Didática. São Paulo: Cortez.

Loguercio, R. Q., \& Del Pino, J. C. (2006). Contribuições da história e da Filosofia da Ciência para a construção do conhecimento científico em contextos de formação profissional de Química. Acta Scientiae, 8(1), 67-77.

Luckesi, C. C. (1994). Filosofia da educação. São Paulo: Cortez.

Manfredi, S. M. (1993). Metodologia do ensino: diferentes concepções. Campinas: F. E./ UNICAMP, mimeo.

Manzini, E. J. (2010). Jogos e recursos para comunicação e ensino na educação especial. Marília: ABPEE.

Marconi, M. A., \& Lakatos, E. M. (2011). Metodologia Científica. São Paulo: Atlas.

Martins, R. F. R. C. (1984). Acerca do conceito de estratégia. Nação e Defesa, 29, 98-125.

Masetto, M. T. (2012). Competência pedagógica do professor universitário. São Paulo: Summus Editora.

Menegolla, M., \& Sant’Anna, I. M. (2014). Por que planejar? Como Planejar? Petrópolis: Vorazes.

Monteiro, I. G., \& Justi, R. S. (2000). Analogias em livros didáticos de química brasileiro destinados ao ensino médio. Investigações em Ensino de Ciências, 52(2), 67-91.

Moreira, M. A. (2006). Mapas conceituais e diagramas V. Recuperado de: http://www. mettodo.com.br/ebooks/Mapas_Conceituais_e_Diagramas_V.pdf

Morin, E. (2005). Introdução ao pensamento complexo. Rio de Janeiro: EuroAmerica. 2005. 
Petrucci, V. B. C., \& Batiston, R. R. (2006). Estratégias de ensino e avaliação de aprendizagem em contabilidade. In Peleias, I. R. (Org.) Didática do ensino da contabilidade. São Paulo: Saraiva.

Piletti, C. (2004). Didática Geral. São Paulo: Editora Ática.

Ribeiro, L. R. de C. (2005). Aprendizagem Baseada em Problemas (PBL): uma implementação na educação em engenharia na voz dos atores. (Tese de Doutorado em Educação). Centro de Educação em Ciências Humanas, Universidade Federal de São Carlos, São Carlos.

Rios, T. A. (2006). Competência e Qualidade na docência. In T. A. Rios. (Orgs.) Compreender e ensinar por uma docência da melhor qualidade (pp. 63-92). São Paulo: Cortez.

Sá, L. P., Francisco, C. A., \& Queiroz, A. L. (2007). Estudos de caso em Química. Química Nova, 30(3), 731-739. http://dx.doi.org/10.1590/S0100-40422007000300039

Sánchez Blanco, G., \& Valcárcel Pérez, M. V. (1993). Diseño de Unidades Didácticas em el área de Ciencias Experimentales. Enseñanza de las Ciencias, 11(1), 33-44.

Sánchez Blanco, G., \& Valcárcel Pérez, M. V. (1993). Science Teachers' Views and Practices in Planning for Teachin. Journal of Research in Science Teaching, 36(4), 493-513.

Sanmartí, N. (2002). Didactica de las ciencias en la educación secundaria obligatoria. Madrid: Síntesis.

Sant'Anna, I. M., \& Sant' Anna, V. M. (2014). Recursos educacionais para o ensino: quando e por quê? Petrópolis: Vozes.

Sant’Anna, I. M., \& Menegolla, M. (2011). Didática: Aprender a ensinar. São Paulo: Editora Loyola.

Santos, W. L. P., \& Mortimer, E. F. (2002). Uma análise de pressupostos teóricos da abordagem C-T-S (Ciência - Tecnologia- Sociedade) no contexto da educação brasileira. Ensaio - Pesquisa em Educação em Ensino de Ciências, 2(2), 110-132. http://dx.doi. org/10.1590/1983-21172000020202

Ustra, S. R. V., \& Hernandes, C. L. (2010). Enfrentamento de problemas conceituais e de planejamento ao final da formação inicial. Ciência \& Educação, 11(3), 723-733. http:// dx.doi.org/10.1590/S1516-73132010000300015

Vieira, R. M., \& Vieira, C. (2005). Estratégias de ensino/aprendizagem. Lisboa: Instituto Piaget.

Veiga, I. P. A., Damis, O. T., Lopes, A. O., Lima, M. E., Castanho, M., Martins, P. L. O., \& Cunha, M. I. (1992). Repensando a didática. Campinas: Papirus.

Vigotski, L. S. (2009). A construção do pensamento e da linguagem. São Paulo: WMF Martins Fontes. 
Villani, A., Dias, V. S., Valadares, J. M. (2010). The development of Science Education Research in Brazil and Contribution from the History and Philosophy of Science. International Journal of Science Education, 32(7), 907-937. http://dx.doi. org/10.1080/09500690902855711

Zabala, A. (1998). A prática educativa. Porto Alegre: Artmed.

\section{Milena Alves}

https://orcid.org/0000-0002-7867-7877

Universidade Estadual Paulista Júlio de Mesquita Filho

Instituto de Química Araraquara, São Paulo, Brasil milena.alves1@unesp.br

Amadeu Moura Bego

https://orcid.org/0000-0001-9182-1987

Universidade Estadual Paulista Júlio de Mesquita Filho Instituto de Química Araraquara, São Paulo, Brasil amadeu.bego@unesp.br

Submetido em 01 de julho de 2019 Aceito em 30 de dezembro de 2019

Publicado em 21 de fevereiro de 2020 